\section{References}

AUDIT COMMISSION (1999) Children in Mind: Child and Adolescent Mental

original papers
Health Services. London: Audit Commission.
- \& GOWERS S. G. (1999) Use of an adolescent in-patient unit. Advances in Psychiatric Treatment, 5, 192-201.

\section{DEPARTMENT OF HEALTH (1999)}

National Service Framework for Mental Health. Modern Standards \& Service

Models. London: Department of

Health.
NHSHEALTH ADVISORY SERVICE (1986) - (1995) Together We Stand. London: Bridges OverTroubled Waters. A Report NHS Health Advisory Service. fromThe NHS Health Advisory Service on Services for Disturbed Adolescents. London: NHS Health Advisory Service.

\title{
Using the internet as a source of self-help for people who self-harm
}

\begin{abstract}
AIMS AND METHOD
To describe the information and help available on the internet for people who self-harm. We searched the internet using a meta-search engine. We visited sites and followed up links with e-mails and letters. We also searched bibliographic databases, seeking published material about the internet and self-harm.
\end{abstract}

\author{
RESULTS \\ The support that we found largely \\ took the form of information about \\ suicide, self-injury and psychological \\ issues. Less often, sites offered \\ e-mail support and online discus- \\ sions. We found little information \\ about self-poisoning, and most \\ about self-injury. There is little \\ published research about self-harm \\ and the internet.
}

\author{
CLINICAL IMPLICATIONS \\ The unregulated sites of the internet \\ contain much material about self- \\ injury. Although it is not possible at \\ present to weigh up risks and \\ benefits, many individuals and \\ organisations plainly regard internet \\ information about self-harm as a \\ valuable service.
}

Hospital contacts for self-harm in the UK are higher now than at any time (Hawton et al, 1997) and may account for more than 150000 hospital attendances in the UK each year. Many more episodes do not lead to hospital attendance. In recent years the internet has been a growing resource for information and communication, used increasingly by patients. Aware that many people who undertake self-harm seek and find ways of reducing their distress, we wanted to investigate, characterise and describe to medical professionals the help resources available on the internet for people who self-harm. We attempted to search the internet systematically, rather as one might undertake a conventional systematic review of published literature.

\section{The study}

\section{Web searching}

Our first step was to use the search engine metacrawler (http://www.metacrawler.com). This is a 'meta'-search engine that works by querying the other search engines, organising the results into a uniform format, ranking them by relevance and returning them to the user. It combines the results of several search engines (about.com, altavista, excite, goto.com, infoseek, looksmart, lycos, thunderstone, webcrawler and yahoo!). We searched the term DELIBERATE SELF-HARM followed by DELIBERATE SELF HARM; they brought similar results.
We searched for DELIBERATE SELF HARM on three separate days to discover whether time lapse would yield significantly different results. We also searched the terms ATTEMPTED SUICIDE and SUICIDE SELF HELP and performed a search for the phrase HOW TO COMMIT SUICIDE. In addition, we used the facilities provided by http://www.about.com - a network of websites organised by 'expert guides'.

We visited a site if the annotations under the title of its page suggested that it would provide self-help for people who self-harm. We followed links within sites with the same strategy. Where we obtained information that pointed to sources of further information we (V.P.) contacted the sources by e-mail or letter, explaining the nature of the study and requesting further information. At no time did the searcher enter discussion forums because of the ethical considerations: these forums offer help and are not aimed at health professionals. In the Findings, set out below, we have selected, from the scores of sites found, a few examples that we think illustrate the characteristics of self-harm related websites, and ones that we think may be useful resources.

\section{Searching for published literature about} self-help on the internet

Medline was searched from 1997 to March 2000. The subject terms DELIBERATE SELF HARM, SELF-INJURIOUS 
BEHAVIOUR and SUICIDE, ATTEMPTED were searched in stages and then combined. A separate search of SELF HELP and INTERNET was also combined. The results of these two search strategies were then combined.

We also searched ClinPSYC - produced by the American Psychological Association and comprising references with abstracts from journal literature in clinical and medical psychology - between the dates 1989 and March 2000 (information about ClinPSYC can be viewed through the Ovid Technologies website at http:// www.ovid.com/sales/medical.cfm). The terms DELIBERATE SELF HARM, SELF DESTRUCTIVE BEHAVIOUR and ATTEMPTED SUICIDE were searched. The term 'self help' gave an unsatisfactory response so we successfully searched the term SUPPORT GROUPS. This result was combined with those for the above three self-harm terms.

\section{Findings}

\section{Web searching}

\section{Search for DELIBERATE SELF-HARM, DELIBERATE SELF HARM}

The search for DELIBERATE SELF HARM yielded 31, 34 and 37 hits on successive occasions. Useful sites included the young people and self-harm information resource http://www.ncb.org.uk/selfharm/shgenaa.htm. This is a database containing listings of initiatives that relate to children, adolescents and young adults aged under 20 who physically injure themselves. We found these initiatives to consist mainly of individuals and groups who wanted to share their experience of self-harm, research teams and many who were involved in self-harm related clinical projects within health services (particularly within the NHS). We (V.P.) wrote for further information about self-help availability to appropriate entries in the database.

We found many self-harm related sites on the Bodies Under Siege WebRing (to be found by searching http://www.webring.org). Among them are sites giving personal accounts of self-cutting and personal webpages of those who self-harm. For example, http:// www.geocities.com/wellesley/garden/7998/index.htm is a webpage about someone's personal experience of self-harm - coping the best you can. This page also has a link to another page - secret shame (http:// www. palace.net/ llama/psych/injury.html), which gives advice and has a self-help section. The self-help advice is practical, including advice on how to stop self-harming, obtaining helpful first aid and avoiding post-traumatic stress disorder. An example of the sort of guidance given is, "you are doing nothing shameful". In order to place readers into categories the page asks the user to answer a list of questions about what they feel like doing, such as: "what are you feeling ... wanting to see scars or pick scabs". It might then advise a course of action: for example, "get a henna tattoo kit". The site has a section for interactive areas - providing links to other pages, such as the Bodies Under Siege WebRing and chat rooms where people can exchange messages online. http://www.gurlpages.com/zines/grrrlyzine/ cut $2 \mathrm{~h} . \mathrm{html}$ is an example of a site that has a great many links to poems, accounts of personal experiences and questions about self-harm, arranged in alphabetical order. This site also has a link to the message board that is part of the Bodies Under Siege WebRing. Another site with several self-harm related sites within it is http:// www.angelfire.com. One example of the kind of self-help provided is a personal homepage that is written by someone who self-harms. The author does not hold formal qualifications for providing psychological help but says he is qualified to do so by his experiential knowledge. It sets out reasons why not to self-injure and offers advice for those who are going to injure themselves. There is provision for people to e-mail the author for online support or e-mail advice.

\section{Search for ATTEMPTED SUICIDE}

The search for ATTEMPTED SUICIDE gave 68 results. One search engine, Google, 'timed out'. The pages that were yielded by this search included http:// www.members.tripod.com/ kittn/index.html, whose homepage sets out reasons why not to commit suicide. The page has a disclaimer: "This page is for information only and is not intended to be used as a substitute for a consultation with a medical professional." It goes on to give information about what to look for in a friend who may be suicidal, how to help such a person and phone numbers, books and other links. Its links are mainly to sites that give information about suicide and depression.

\section{Search for SUICIDE SELF HELP}

This search yielded 50 results and the search engine Lycos timed out. The results included the Suicide Prevention Triangle (SPT), http:// www.suicidepreventtriangle.org, which has a number of self-help tools; such as their SPT assessment - to assess one's current need for counselling; a satisfaction scale that measures the wish to live; and a measure of significant loss that measures the triggers of distress. Once again it offers up a number of quotes from survivors.

The site called the 'self-help corner' (http:// www.queendom.com/selfhelp) offers links to a variety of self-help sites aimed at psychological needs. It draws particular attention to self-help for those considering a suicide attempt. The reader is directed to appropriate links from a banner heading: "If you are suicidal... read this first...". The reader is then given supportive information and there are links to other organisations (including the Samaritans and Befrienders International), suicide helplines and suicidology helplines. The Befrienders International site, http:// www. befrienders.org, states that they have 31000 volunteers in over 40 countries. They are able to give information on helplines in the user's country and e-mail support in various languages. Their English language e-mail support is provided by UK Samaritans. At http:// www.hollandcrosspsych.com/suicide.htm there are links to many US and Canadian sites. http:// www.virtualcity.com/youthsuicide/gbsuicide. htm is a site 
that provides a great deal of information about (with masses of referenced summaries of published papers concerning the epidemiology of) gay and bisexual male suicide and attempted suicide - as well as links to relevant self-help sites.

\section{Search for HOW TO COMMIT SUICIDE}

This search yielded 75 results but, when we followed up the links that we could call up on to screen, none gave us information on how to commit suicide. The pages included copious information from religious groups discouraging suicide, one notable example telling readers that those who commit suicide will go to Hell where they will be more miserable than they think they are now.

\section{Searching for published literature about self-help on the internet}

Despite many hundreds of hits from individual search terms, when Medline and ClinPSYC search terms about self-harm and suicide were combined with the terms about self-help and support groups and about the internet, only one reference emerged. We concluded that there was little published literature about internet or other self-help for self-harm. We found a personal account of a service-user and a health professional's experience with self-harm (Rowden \& Pembroke, 1999).

\section{Correspondence}

We sent eight letters and approximately 30 e-mails. Three people replied to the letters and approximately 10 replied to e-mail. Most of the replies directed us back to search engines or websites that we had already found. Only one site was recommended by e-mail that we had not seen already as a result of the searches. One paper about suicide and the internet arrived by post that had not emerged from our Medline or ClinPSYC searches (Alao et al, 1999).

\section{Discussion}

We used a 'meta' search engine that combined several other search engines. As an alternative we might have used a search engine such as 'Google' (http:// google.com), which ranks hits according to the number of links that there are to a certain site, rather than the number of times the search term is found within a particular site. Another advantage of Google is its strategy of grouping all the pages from the same sites together - thus avoiding unnecessary revisits to pages that are part of the same site. We found slight differences in yield with the same search on different occasions: likely to be a sign of the internet's dynamic and constantly changing composition.

Internet searching is limited by the restriction to search only by specific words. Mapping to subject headings, available in Medline and other database searches, is not possible on the internet. Consequently, we could have expanded and strengthened the investigation by searching the internet for specific types of self-harm, such as 'cutting' and 'poisoning'. Search engines also allow advanced searching with the combination of search terms with AND and OR commands, or by searching for whole phrases. However, we were reassured that we had achieved a reasonably representative search of relevant websites by two occurrences: searches using different strategies yielded more repeat sites than new ones and replies to our correspondence mainly pointed towards sites we had already found.

Our findings led us to three main conclusions. First, we formed the impression that self-help for those who self-harm provided through the internet mainly takes the form of information, guidance and advice: suggestions intended to be constructive, illustrations from the experience of others in a comparable position, guidance about how to overcome shameful feelings about selfharm, advice on how to feel better about oneself and pointers to whom to contact for direct assistance. Only infrequently did the help offer direct on-line exchange of views or support through channels such as e-mail with someone, or by entry into a discussion forum. This pattern of help is similar to that available to patients with cancer, which may take the form of suggesting how to overcome the negative emotions of chemotherapy and how to cope by using techniques such as distraction (Prasad, 2000).

Second, although around nine out of 10 hospital contacts resulting from self-harm involve self-poisoning, we found few sites that dealt with self-poisoning compared with many concerned with self-injury. Reasons for the contrast are not clear but are likely to involve factors like differences in the motives; differences in the likelihood of looking towards external help or self-help; differences in the responses of family, friends and public; differences in the risk to life; and differences in hospital services and staff attitudes.

Third, we did not find the internet an easy source of explicit information on how to commit suicide. But with different searching strategies others have located such information and this concern must remain plausible (Alao et al, 1999). Rather, to the contrary, the pages we perused, and the replies to the e-mails we sent, were warnings that discussion groups and forums on their sites may contain 'trigger' information (which might advocate or unwittingly encourage self-injurious behaviour by the reader) and that the existence of such information was outside the control of page or site authors.

We concluded that professionals involved with people who self-harm would benefit from knowing something about the kind of material available to those who visit websites; we hope to have assisted them here, or at least prompted them to their own exploration of the web. But we also felt that the professionals involved need to understand more clearly than they do at present 
how helpful, disconcerting or harmful people find the sites - whether as visitors, participants in discussion forums, or page authors.

It is not possible to regulate the internet and one cannot exclude the possibility of misinformation or of people obtaining information that may be unhelpful or even harmful to them. The present enquiry has not evaluated the benefits or risks of internet sites about self-harm. Any future research of online support groups will pose ethical issues for the researcher (Klemm \& Nolan, 1998). For example, much of the information provided by the internet is already in the public domain, but the extent to which it should properly be quoted in the medical literature is another matter. The originators of information did not put it there for the benefit of researchers or medical professionals and there are important issues of personal confidentiality and identity.

\section{References}

ALAO, A. O., YOLLES, J. C. \& ARMENTA, KLEMM, P. \& NOLAN, M.T. (1998) W. (1999) Cybersuicide: the internet Internet cancer support groups: legal and suicide. American Journal of and ethical issues for nurse researchers. Psychiatry, 156, 1836-1837. Oncology Nursing Forum, 25,

HAWTON, K., FAGG, J., SIMKIN, S., et al (1997) Trends in deliberate self-harm in Oxford, 1985-1995. Implications for clinical services and the prevention of suicide. British Journal of Psychiatry, $171,556-560$ 673-676

PRASAD, V. (2000) Cancer self-help groups. Yorkshire Medicine, 12, 92-95. ROWDEN, R. \& PEMBROKE, L. (1999) Face to face. Nursing Times, $95,38-39$

Vibhore Prasad Medical Student " *David Owens Senior Lecturer in Psychiatry, Academic Unit of Psychiatry and Behavioural Sciences, University of Leeds School of Medicine, 15 HydeTerrace, Leeds LS2 9LT 